\title{
KONSEP KARAKTER UTAMA PADA BUKU CERITA BERGAMBAR ASAL MULA POHON ENAU DARI BENGKULU
}

\author{
Noer Anna Della ${ }^{1)}$, Winny Gunarti Widya Wardani ${ }^{2)}$, Febrianto Saptodewo ${ }^{3)}$ \\ Program Studi Desain Komunikasi Visual, \\ Fakultas Bahasa dan Seni, Universitas Indraprasta PGRI \\ Jl. Nangka No. 58 C, Tanjung Barat, Jakarta 12530, Indonesia \\ annadellanoer96@gmail.com
}

\begin{abstract}
Abstrak
Cerita rakyat Pohon Enau berasal dari Bengkulu. Cerita rakyat ini bercerita tentang seorang gadis yang meninggal dunia dan di pusara makamnya tumbuh sebuah pohon yang belum pernah ada sebelumnya. Pohon itu bernama pohon Sedaro Putih, kini dikenal dengan nama Pohon Enau. Metode yang digunakan dalam perancangan ini adalah metode kualitatif, dengan mengumpulkan data melalui penelitian, buku-buku, dan jurnal. Tujuan dari perancangan ini, agar anak-anak dapat mengenal cerita rakyat asal mula Pohon Enau lewat karakter utama yang dibuat. Cerita ini memiliki pesan moral tentang hidup yang bermanfaat. Pesan moral ini baik untuk diterapkan kepada anak-anak lewat tokoh-tokoh yang ada di dalamnya. Melalui visualisasi gambar yang diharapkan anak-anak dapat menyerap pesan moral yang ada di dalam cerita rakyat tersebut.
\end{abstract}

Kata Kunci: Cerita Rakyat, pohon Enau, Bengkulu, Anak-anak, karakter.

\begin{abstract}
Enau Tree folklore is from Bengkulu. This folklore telling about a girl who passed away and her tomb grows a tree. That has never existed before the tree is named Sedaro Putih, and now this tree as known Enau Tree. The meaning of this story is usefull life. Methode for use in this design is kualitatif methode, with collect the data from thorough, books, and journal. The purpose of this design, so that children can get to know asal mula Pohon Enau folklore through the main character made. This moral value is good to be applied to children through the caracters in the story. Through visualization in the folklore, it is expected the children can understand the moral value in the Enau Tree folklore.
\end{abstract}

Keywords: Folklore, Enau Tree, Bengkulu, Children, character.

\section{PENDAHULUAN}

Indonesia memiliki banyak sekali keanekaragaman, salah satunya cerita rakyat yang menjadi cerminan dari kekayaan budaya negeri ini. Cerita rakyat Bengkulu adalah salah satu bentuk dari kekayaan budaya Nusantara. Banyak sekali cerita rakyat yang berasal dari daerah ini, salah satunya adalah cerita rakyat asal mula Pohon Enau yang belum banyak dikenal oleh masyakat. Cerita rakyat ini berasal dari Suku rejang di Kabupaten Rejang Lebong, Desa Curup Timur, Bengkulu. Peneliti memilih objek cerita rakyat asal mula Pohon Enau karena cerita tersebut belum seterkenal cerita-cerita rakyat lainnya, padahal cerita ini memiliki pesan moral yang baik untuk anak-anak. 
Cerita ini memiliki pesan moral tentang nilai sosial, yaitu manusia haruslah saling bermanfaat untuk orang lain, sama seperti halnya yang disimbolkan pada Pohon Enau tersebut. Karena pada dasarnya manusia adalah makhluk sosial, yang saling bergantung antarsatu dengan yang lainnya (Utami, 2014: 75).

Pohon Enau sendiri adalah pohon yang memiliki banyak manfaat untuk manusia. Hampir seluruh bagian dari Pohon Enau tersebut dapat digunakan untuk berbagai kebutuhan, baik fisik maupun bagian produksinya. Pohon Enau atau aren adalah salah satu jenis tumbuhan pala yang memproduksi buah, nira, dan pati tepung di dalam batang (Lempang, 2012: 44). Pesan moral tersebut sesuai dengan manfaat Pohon Enau yang memiliki banyak mafaat terhadap kehidupan manusia.

Oleh karena permasalahan tersebut, peneliti nantinya akan merancang sebuah media berupa buku cerita bergambar sebagai solusi agar masyarakat dapat mengenal cerita rakyat asal mula Pohon Enau khususnya para anak-anak yang menyukai dominasi visual gambar. Namun, dalam penelitian ini, peneliti hanya menyajikan penciptaan karakter utama sebagai karakter yang dapat menarik perhatian pembaca.

\section{METODE PENELITIAN}

Jenis penelitian yang digunakan yaitu penelitian kualitatif. Metode kualitatif adalah suatu proses penelititan yang dilakukan secara wajar dan natural sesuai dengan kondisi objektif di lapangan tanpa adanya sebuah manipulasi, serta jenis data yang dikumpulkan terutama data kualitatif (Arifin, 2011: 140). Penelitian ini bertujuan untuk membuat suatu perancangan Karakter tokoh buku cerita bergambar asal mula Pohon Enau. Buku yang menjadi referensi utama dalam pembuatan karakter cerita rakyat asal mula Pohon Enau ini adalah buku karangan Syamsuddin, dkk. Buku ini berisikan tentang cerita-cerita rakyat yang berasal dari Bengkulu. Di dalam buku ini terdapat cerita rakyat Pohon Enau yang menjadi literatur utama dalam pembuatan tokoh tersebut.

Perancangan karakter utama dalam cerita bergambar ini mengacu pada teori morfologi bentuk. Morfologi menurut KBBI dalam cabang ilmu Biologi, mengarah pada ilmu pengetahuan tentang bentuk luar dan susunan makhluk hidup. Dengan demikian, morfologi yang dimaksud adalah pembuatan fisik tokoh dalam perancangan karakter utama yang ada dalam buku cerita bergambar asal mula Pohon Enau tersebut.

\section{HASIL DAN PEMBAHASAN \\ Pengertian Karakter}

Menurut Estidianti dan Lakoro (dalam Yazid, 2018: 3) menjelaskan bahwa karakter terdiri dari semua karakter yang mendukung jalannya cerita tersebut, antara lain berupa karakter protagonis, antagonis, dan karakter pembantu. Karakter adalah sebuah hasil dari pemikiran penciptanya yang didasari dari sebuah inspirasi, baik kejadian yang dirasakan langsung oleh sang pencipta, maupun hasil dari stimulus membaca sebuah cerita dalam karya literatur atau bidang seni lainnya seperti halnya musik dan juga film. Menurut Saptodewo (2018: 79) desain karakter bisa lahir dari berbagai konsep dan tujuan serta media atau dari platform apa media itu akan "hidup". Karakter desain bisa lahir dari sebuah gagasan yang "pure art" atau dapat dikatakan lahir tanpa kepentingan apa pun. Sebagaimana karya seni dan desain lainnya, desain karakter tidak dibuat secara instan, tetap ada sebuah proses yang harus dilalui agar karakter nantinya dapat menyampaikan pesan yang dikandung kepada audiens secara efektif.

Jadi, dapat disimpulkan bahwa perancangan visual sebuah karakter harus disesuaikan pada sifat-sifat yang tertanam dalam peranan karakter tersebut, seperti yang telah di jelaskan sebelumnya. Namun, karakter tersebut tidak lepas dari peran pencipta masing-masing yang membuat karakter menjadi memiliki ciri khas tersendiri karena dibuat oleh para pencipta yang berbeda-beda di setiap pembuatan karakter yang lain.

Cerita Rakyat Asal Mula Pohon Enau adalah kisah dari seorang Putri bernama Putri Sedaro Putih, ia memiliki enam orang kakak laki-laki yang sangat menyayanginya. Ia bermimpi jika akan tumbuh sebatang pohon yang belum pernah ada sebelumnya di pusara makamnya saat 
ia meninggal nanti. Hingga pada saatnya, ia meninggal dunia dan tumbuh sebatang pohon yang belum pernah ada sebelumnya. Pohon tersebut diberi nama Sedaro Putih oleh para kakaknya dan kini pohon tersebut dikenal dengan nama Pohon Enau.

Terdapat tiga karakter utama yang ada di dalam cerita rakyat tersebut, antara lain Putri Sedaro Putih, Kakak Sulung, dan salah satu dari kelima kakak tersebut selain kakak sulung. Putri Sedaro Putih memiliki karakter sifat yang baik hati, jujur, dan rela berkorban. Sang kakak sulung memiliki karakter sifat yang peduli terhadap Putri karena ia selalu memikirkan psikologis Putri saat Putri mendapat mimpi tersebut, dan salah satu kakak dari Putri Sedaro Putih memiliki sifat kreatif karena ia mampu memecahkan masalah terhadap Pohon Enau yang ternyata dapat bermanfaat untuk orang banyak.

\section{Analisis Khalayak}

Dalam perancangan karakter tokoh buku cerita bergambar asal mula Pohon Enau ini di lakukan analisis khayalak terlebih dahulu, agar visualisasi tersebut dapat tersampaikan kepada target yang tepat. Berikut ini adalah anlisis khalayak yang peneliti lakukan, yaitu:

1. Segmentasi

Perancangan karakter tokoh cerita buku bergambar asal mula Pohon Enau ini ditujukan untuk anak-anak berumur enam hingga sepuluh tahun yang hidup di daerah perkotaan. Dikhususkan untuk anak-anak yang menyukai aktivitas membaca buku dan melihat visualisasi gambargambar.

\section{Targeting}

Perancangan karakter asal mula Pohon Enau ini ditujukan untuk mayoritas anak-anak berumur tujuh tahun yang gemar dengan aktivitas membaca buku cerita bergambar dan tinggal di kota-kota besar.

\section{Positioning}

Perancangan karakter tokoh asal mula Pohon Enau ini divisualisasikan sesuai dengan isi cerita rakyat asal mula Pohon Enau yang karakternya dapat mencerminkan sesuai pada apa yang diperankan.

\section{Proses Perancangan}

Proses perancangan mengacu pada teori morfologi bentuk, yaitu mengarah kepada pengetahuan tentang bentuk luar dari susunan makhluk hidup, atau bisa disimpulkan bahwa teori tersebut mengacu pada bentuk fisik makhluk hidup. Jadi, bentuk fisik tersebut adalah bentuk dari para karakter yang dibuat pada buku cerita bergambar asal mula Pohon Enau tersebut. Teknik yang digunakan dalam perancangan ini adalah digital. Proses awal yang digunakan adalah menggambar manual, lalu di diselesaikan dengan menggunakan software Adobe Ilustrator.

Karakter yang digunakan dalam perancangan ini lebih mengarah pada karakter kartun. Karakter dibuat menonjol dalam sisi ciri khas adat Bengkulu lewat penerapan pakaian adat yang diaplikasikan kepada para tokoh tersebut. Terdapat beberapa elemen desain yang ada di dalam pembuatan Karakter dalam buku cerita bergambar asal mulai Pohon Enau ini. Elemen tersebut antara lain, yaitu warna, garis, dan ukuran pada karakter.

Menurut Listya (2018: 10) warna telah lebih dulu dipersepsikan sebelum bentuk dikenali, sehingga dapat dikatakan bahwa warna adalah elemen yang wajib dalam sebuah desain, karena jika tanpa warna maka elemen lainnya dapat dikatakan tidak ada. Warna yang digunakan dalam perancangan pembuatan tokoh karakter ini adalah warna-warna pastel yang terlihat ceria. Karena karakter ini ditujukan untuk target anak-anak berumur enam hingga sepuluh tahun. Di umur tersebut, anak-anak lebih menyukai warna-warna ceria yang terang, saat itu adalah umur yang tepat untuk anak-anak mengenal berbagai macam warna lewat karakter tokoh asal mula Pohon Enau.

Garis-garis yang digunakan dalam perancangan ini lebih didominasi oleh garis-garis melengkung agar karakter tidak terkesan kaku dan terlihat luwes. Ukuran karakter memiliki 
perbandingan yang berbeda antara ukuran tubuh dan kepala. Ukuran kepala dibuat lebih besar dibanding ukuran tubuh karakter karena peneliti ingin menekankan kesan desain karakter cibi. Karakter ini biasanya disukai oleh anak-anak, karena bentuknya yang terlihat mungil.

Berikut ini adalah sketsa kasar pada perancangan karakter dalam buku cerita bergambar asal mula Pohon Enau, yaitu:

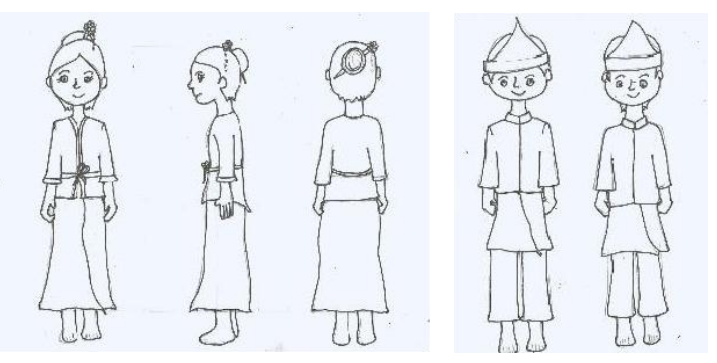

Gambar 1 Sketsa Kasar Desain Karakter Buku Cergam Asal Mula Pohon Enau Sumber: Dokumen Pribadi

Karakter Putri, dibuat menjadi tiga bagian karena ia adalah tokoh utama dalam cerita asal mula Pohon Enau tersebut. Semua karakter tersebut berbentuk kartun dan mengacu pada jenis kartun cibi karena perbandingan struktur morfologi bentuk bagian tubuh dan kepala yang tidak seimbang (bentuk kepala terlihat lebih besar). Semua tokoh memakai pakaian khas adat Bengkulu yang telah disederhanakan karena mengacu pada kehidupan sehari-hari para karakter tersebut.

\section{Hasil Rancangan}

Berikut ini adalah hasil rancangan karakter tokoh-tokoh yang ada di dalam buku cerita bergambar asal mula Pohon Enau dari Bengkulu, anta lain:

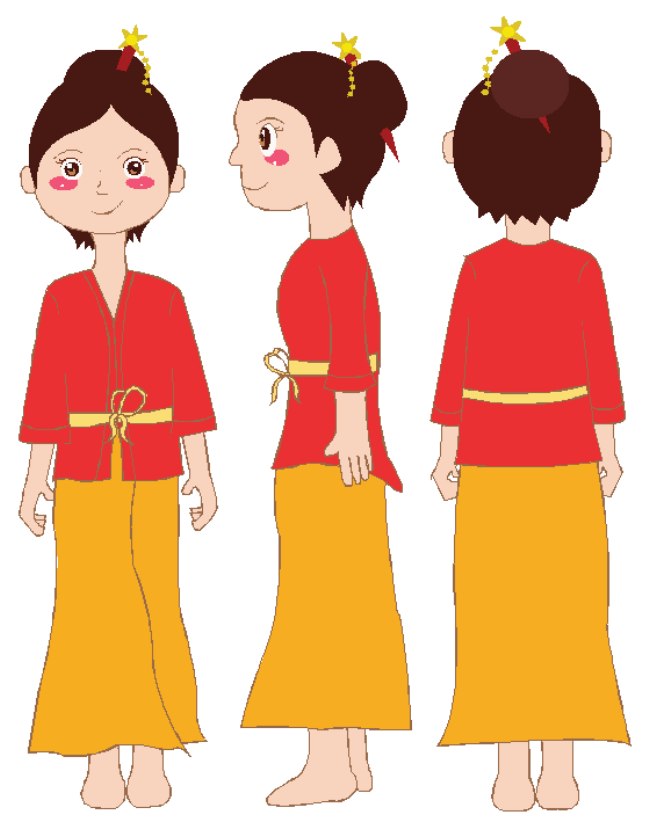

Gambar 2 Desain Karakter Putri Sedaro Putih Sumber: Dokumen Pribadi

Gambar 2 adalah Karakter tokoh utama cerita rakyat asal mula Pohon Enau dari Bengkulu. Tokoh ini bernama Putri Sedaro Putih. Ia memiliki karakter sifat lugu, baik hati, dan tulus. Sang Putri menggunakan pakaian khas adat Bengkulu yang telah disederhanakan karena digunakan dalam aktivitas sang Putri di kesehariannya. 


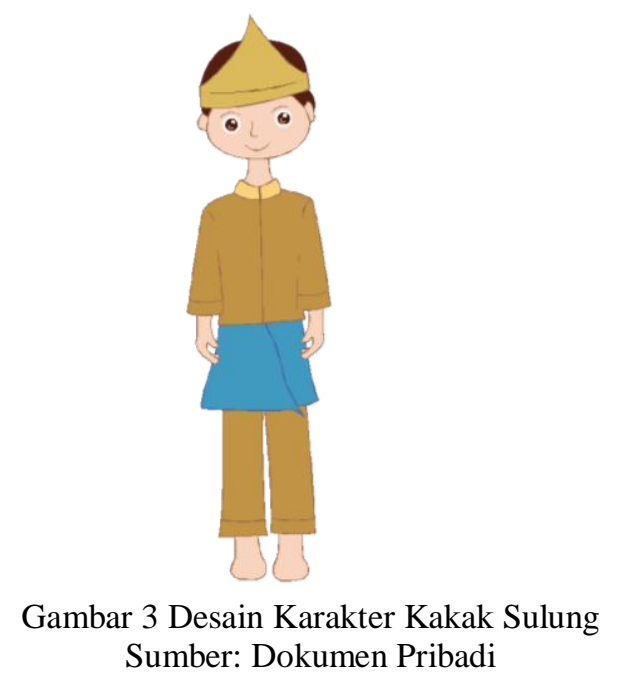

Gambar 3 adalah karakter tokoh dari kakak sulung Sang Putri. Tokoh ini tidak memiliki nama, hanya memiliki bentuk panggilan saja. Kakak Sulung memiliki karakter sifat yang bijaksana dan pengertian karena ia adalah pengganti kedua orang tuanya di dalam cerita tersebut. Ia memakai pakaian adat Bengkulu dan juga menekankan pada pengaplikasian topi khas Bengkulu yang bernama Detar. Pakaian adat ini telah disederhanakan karena berhubungan dengan aktivitas sehari-hari sang tokoh.

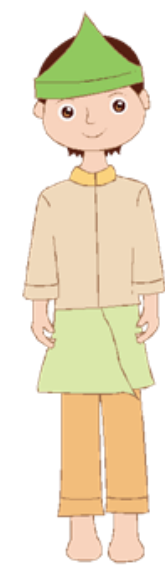

Gambar 4 Desain Karakter Salah satu Kakak Putri Sumber: Dokumen Pribadi

Gambar 4 adalah karakter tokoh dari Salah satu kakak Putri Sedaro Putih. Sama dengan kakak sulung, ia juga tidak memiliki nama hanya memilik bentuk panggilan saja. Kakak Sang Putri ini memiliki karakter sifat rasa ingin tahu yang tinggi karena berkat dirinya, melihat suatu kejadian di dalam cerita tersebut, ia dan para saudaranya dapat memanfaatkan Pohon Enau dengan sebaik mungkin. Kakak sang Putri ini sama menggunakan pakaian adat Bengkulu yang telah disederhanakan.

\section{SIMPULAN}

Pesan moral yang terdapat pada asal mula Pohon Enau tentang simbol hidup yang bermanfaat, penting untuk ditanamkan pada semua orang khususnya anak-anak. Manusia pada hakikatnya harus dapat bermanfaat untuk orang lain di sekitarnya, seperti Pohon Enau yang menyimbolkan kebermanfaatan untuk orang di sekitarnya. 
Dalam perancangan karakter pada buku cerita bergambar asal mula Pohon Enau ini, dapat disimpulkan bahwa karakter yang dirancang disesuaikan pada target khalayak yang dituju, yaitu anak-anak, dengan mengacu pada teori morfologi bentuk dan juga elemen desain di dalamnya agar tercipta karakter yang sesuai untuk cerita bergambar tersebut.

Adapun pesan yang dapat disampaikan melalui karakter utama tersebut adalah sifat rela berkorban, jujur, peduli, dan dapat memecahkan masalah. Perancangan karakter ini dapat menjadi sebuah ide baru yang terdapat pada sifat tiga karakter utama asal mula Pohon Enau ini.

\section{DAFTAR PUSTAKA}

Arifin, Z. (2011). Penelitian pendidikan metode dan paradigma baru. Bandung: Rosda Karya.

Lempang, M. (2012). Pohon aren dan manfaat produksinya. Buletin Eboni, 9(1), 37-54.

Listya, A. (2019). Konsep dan pengunaan warna dalam infografis. Jurnal Desain, 6(01), 10-19.

Saptodewo, F. (2018). Perancangan karakter bregada keraton Yogyakarta sebagai media visual pendukung photo booth. Jurnal Desain, 5(02), 74-85.

Utami, T. W. (2014). Analisis deskriptif karakter positif dalam cerita rakyat Bengkulu yang sesuai dengan usia anak sd. (Skripsi). Fakultas Keguruan dan Ilmu Pendidikan, Universitas Bengkulu, Bengkulu.

Yazid, M., Afriwan, H., \& Faisal, D. (2018). Perancangan desain karakter urang bunian dalam budaya Minangkabau melalui media art book. DEKAVE: Jurnal Desain Komunikasi Visual, 7(2). 1-15. 